\title{
A Criminalidade no Rio Grande do Sul: Análise Exploratória de Dados Espaciais para os Anos de 2002, 2010 e 2018
}

Crime in Rio Grande do Sul: An Exploratory Analysis of Spatial Data for the Years 2002, 2010 and 2018

\author{
Fernando Theodoro Guimarães ${ }^{a}$ \\ Kalinca Léia Becker ${ }^{b}$
}

\begin{abstract}
Resumo: O objetivo deste trabalho é analisar a distribuição espacial das taxas de roubos, tráfico de entorpecentes e os homicídios no Rio Grande do Sul nos anos de 2002, 2010 e 2018. Para isso foi utilizado o instrumental da análise exploratória de dados espaciais (AEDE). Os resultados indicaram a existência de intensa correlação espacial para as altas taxas de crimes na Região Metropolitana de Porto Alegre (RMPA), enquanto as baixas taxas de crimes se mostraram correlacionadas nas regiões Nordeste e Noroeste do Estado. Os resultados também apontam que as taxas de roubos e tráfico apresentam maior grau de associação espacial.
\end{abstract}

Palavras-chave: Crime; Economia Regional; Econometria Espacial.

JEL: K14, R11, D91, C21.

\begin{abstract}
This study aims to analyze the spatial distribution of the rates of robberies, narcotics trafficking and homicides in Rio Grande do Sul in the years 2002, 2010 and 2018. For this, the instruments of exploratory analysis of spatial data (AEDE) were used. The results indicated the existence of an intense spatial correlation for the high crime rates in the Metropolitan Region of Porto Alegre (RMPA), while the low crime rates were correlated in the Northeast and Northwest regions of the State. The results also point out that the theft and trafficking rates have a higher degree of spatial association.
\end{abstract}

Keywords: Crime; Regional Economy; Spatial Econometrics.

\footnotetext{
${ }^{a}$ Economista pela Universidade Federal de Santa Maria. E-mail: guimaraesf.theodoro@outlook.com.

${ }^{\mathrm{b}}$ Professora no Departamento de Economia e Relações Internacionais da Universidade Federal de Santa Maria. E-mail: kalinca.becker@ufsm.br.
} 


\section{Introdução}

A criminalidade existe por um amplo conjunto de fragilidades nos fatores estruturais de uma sociedade, como acesso à educação, nível de renda, a definição legal etc. Em termos individuais, a formação moral dos indivíduos também é um condicionante para a atividade ilícita. Entretanto, não há condições que garantam que uma pessoa cometerá ou não crimes, mas é razoável afirmar que determinados contextos favorecem e muitas vezes potencializam a proliferação da delinquência. A complexidade sobre esta temática se dá muito em função de inúmeras variáveis não serem diretamente observáveis.

No Brasil, em virtude da crescente sensação de insegurança e medo com o qual a população convive, pode-se dizer que a criminalidade é um dos principais problemas enfrentados pela sociedade atualmente. Com o aumento crescente de violência letal, este campo de estudo vem gerando diversos debates no que tange a elaboração de políticas públicas que contenham os avanços da violência de maneira rápida e consistente ao longo do tempo.

Os custos econômicos oriundos da criminalidade também chamam atenção. As implicações são altamente danosas ao país, pois incluem a manutenção de estruturas preventivas em todas as esferas de governo, bem como no combate efetivo ao crime. No Brasil em 2015 a criminalidade custou cerca de R\$ 285 bilhões aos cofres públicos. Percentualmente, esses gastos associados ao combate e prevenção da violência representaram um total de 4,38\% da renda nacional (BRASIL, 2018).

Nesse contexto, o Rio Grande do Sul também apresenta cenário preocupante no campo da segurança pública, registrando aumento gradativo de violência letal. Dentro da Região Sul do país, o Rio Grande do Sul é o estado com a maior taxa de crescimento de crimes. De 2010 até 2017 o estado apresentou taxa de homicídios crescente, 5,22\% ao ano, ao passo que em Santa Catarina o aumento foi de 1,83\% ao ano, e o Paraná reduziu em 4,19\% ao ano no período. Se comparado a São Paulo, por exemplo, que possuí hoje os melhores indicadores de violência, o estado gaúcho em 2017 registrou taxa de homicídios 2,85 vezes maior que o estado paulista (ATLAS DA VIOLÊNCIA, 2019).

Apresentado tais informações, é evidente a importância das pesquisas relacionadas à temática do crime, tanto em âmbito nacional quanto regional. Sendo assim, a participação de economistas na área se justifica pela busca empírica das origens e influências da criminalidade, colaborando para o planejamento de políticas públicas efetivas.

No campo da teoria econômica do crime, normalmente se busca elucidar o fenômeno da criminalidade a partir da noção de que os indivíduos que optam em se inserir no mundo do crime são motivados pelos possíveis benefícios oriundos da atividade ilícita em suas variadas formas de compensação frente a outras atividades de atuação no mercado de trabalho legal.

O trabalho desenvolvido por Becker (1968) é a base da análise do crime sob a perspectiva econômica, uma vez que, em seu estudo, os indivíduos escolhem cometer 
crimes ou não em função de suas expectativas sobre os possíveis rendimentos monetários ou seu equivalente, no caso de crimes não econômicos. Os retornos monetários podem variar de acordo com a localidade, seja pela eficiência da justiça e polícia, pelo ganho esperado no crime, custo de planejamento e execução e pelo custo de oportunidade do indivíduo.

Dessa maneira, essa pesquisa buscou responder as seguintes questões: para os crimes considerados, existe autocorrelação espacial no Rio Grande do Sul? Se sim, em quais regiões do estado se formam clusters de criminalidade? Assim, esse trabalho visa identificar os padrões espaciais de criminalidade, bem como sua distribuição pelo estado do Rio Grande do Sul. Foram considerados três tipos de crimes, os homicídios, os roubos e o tráfico de entorpecentes. Os homicídios, apesar de serem essencialmente um crime contra pessoa, seu caráter econômico pode estar associado de maneira velada ao tráfico de drogas em determinados casos. Tais dados são disponibilizados mensalmente pela Secretaria de Segurança Pública do Rio Grande do Sul (SSP-RS). Dessa forma, busca-se examinar a distribuição da criminalidade nos anos de 2002, 2010 e 2018, identificando assim, quais as regiões estão mais vulneráveis à essa atividade.

Esse estudo pretendeu contribuir com a literatura ao analisar crimes de natureza distinta, uma vez que a maior parte da literatura utiliza a taxa de homicídios, e também identificar o deslocamento do crime no território estadual em intervalos de 8 anos, iniciando em 2002, de forma a contemplar todo o período de informações disponíveis.

Além desta introdução, este trabalho foi dividido da seguinte maneira: a segunda seção diz respeito ao corpo teórico que fundamenta Teoria Econômica do Crime; a terceira seção exibe uma série de pesquisas empíricas que retratam as principais relações entre as variáveis econômicas e a criminalidade, bem como suas interpretações; a quarta seção trata dos processos metodológicos adotados na pesquisa, apresentando seus principais detalhes para identificar os clusters de criminalidade; na quinta seção, á última, são tecidos comentários acerca dos resultados da análise exploratória para cada tipo de crime. Por fim, são apresentadas as conclusões.

\section{Referencial Teórico}

Na Ciência Econômica a criminalidade de alguma forma sempre foi trabalhada. Desde seus primórdios, Adam Smith já apontava que a racionalidade das punições deveria se fundamentar no princípio da reparação individual e também no conceito de dissuasão que, por sua vez, são dois pontos cruciais no que viria a ser formalizado por Gary Becker, o principal expoente no campo da Economia do Crime.

O balizamento da Teoria Econômica do Crime é apresentado inicialmente em um artigo de Gary S. Becker, publicado em 1968, denominado Crime and Punishment: an Economic Approach. Seu estudo é o principal arcabouço teórico na abordagem da criminalidade sob perspectiva econômica e, desde então, tem forte influência sobre os estudos acerca da criminalidade e segurança. Becker avalia a atividade criminosa decorrente de uma série de parâmetros sociais e busca a situação ótima do ponto de vista 
da sociedade, considerada como sendo a situação de custo total mínimo (CLEMENTE e WELTERS, 2017).

Os pressupostos teóricos estão micro fundamentados em conceitos marginalistas ${ }^{1}$ da escola neoclássica, ou seja, assumindo o homo economicus condicionado a lógica econômica dicotômica entre os ganhos e os custos associados ao mercado legal e o criminoso, sendo esses mensurados via a utilidade esperada. Vale ressaltar que Becker não engloba questões de cunho intrínseco ao indivíduo como a ética e a moral ${ }^{2}$.

Dito isso, Becker (1968) expõe que o indivíduo se depara com um trade off que, dado seu grau de aversão ao risco, o mesmo decide quanto tempo alocar entre a atividade legal ou criminosa. Sendo assim, se sua utilidade esperada ao cometer um ato delituoso for maior que a utilidade que poderia vir a obter no mercado legal, ele opta por cometer o delito.

Destarte, a teoria econômica do crime desenvolvida por Becker (1968) sugere uma humanização por parte do agente delinquente que, agora, é compreendido como um indivíduo comum, logo reage aos incentivos de forma racional conforme são apresentados. Assume-se que exista uma função que relacione o volume de crimes cometidos por um indivíduo i $\left(\mathrm{O}_{\mathrm{i}}\right)$, Bi representa o benefício em termos monetários associado ao ato criminoso, $\mathrm{Ci}$ o custo de planejamento e execução do crime, Mi o custo moral, Wi indica custo de oportunidade, $\mathrm{P}_{\mathrm{R}}$ a probabilidade de prisão e $\mathrm{P}_{\mathrm{U}}$ a punição. Portanto, a oferta individual de crimes pode ser representada pela seguinte função:

$$
\mathrm{O}_{\mathrm{i}}=\mathrm{O}_{\mathrm{i}}\left(\mathrm{B}_{\mathrm{i}}, \mathrm{C}_{\mathrm{i}}, \mathrm{M}_{\mathrm{i}}, \mathrm{W}_{\mathrm{i}}, \mathrm{Pr}_{\mathrm{i}}, \mathrm{Pu}_{\mathrm{i}}\right)
$$

Sabendo que somente os criminosos que são pegos recebem punição, logo fica evidente a existência de uma "discriminação de preço" e um determinado grau de incerteza acerca da atividade ilícita. Caso seja condenado, o indivíduo i pagará $\mathrm{P}_{\mathrm{U}}$ por seu delito, tal que $\mathrm{P}_{\mathrm{U}}>0$, pelo contrário o mesmo não será penalizado, portanto $\mathrm{P}_{\mathrm{U}}=0$. Com isso, também é possível estabelecer essa relação em termos de utilidade. A utilidade esperada $U_{i}^{E}$ por cometer um crime é definida como:

$$
\mathrm{U}_{\mathrm{i}}^{\mathrm{E}}=\operatorname{Pr}_{\mathrm{i}} \mathrm{U}_{\mathrm{i}}^{\mathrm{E}}\left(\mathrm{B}_{\mathrm{i}}-\mathrm{Pu}_{\mathrm{i}}\right)+\left(1-\operatorname{Pr}_{\mathrm{i}}\right) \mathrm{U}_{\mathrm{i}}^{\mathrm{E}}\left(\mathrm{B}_{\mathrm{i}}\right)
$$

$\mathrm{Na}$ equação (2), o $\mathrm{B}_{\mathrm{i}}$ representa a renda monetária ou sua expectativa decorrente do retorno financeiro da atividade criminosa, $U_{i}$ é sua função de utilidade, $P_{R}$ é a probabilidade de punição e $\mathrm{P}_{\mathrm{U}}$ é interpretado como equivalência monetária da punição.

\footnotetext{
1 "A escola marginalista considera que a satisfação de cada necessidade requer certa quantidade de bem ou serviço. Á medida que a quantidade consumida pelo indivíduo aumenta, reduz-se o aumento da satisfação obtida. A análise de Edgeworth serviu de base para toda a análise marginalista que "supõe pessoas agindo livremente sobre o signo da racionalidade buscando obterem, individualmente, a maior satisfação ou o maior ganho possível. Assim, produtores e consumidores otimizam suas decisões no mercado levando em conta seus objetivos individuais, suas restrições e os objetivos e restrições de todos os outros agentes envolvidos, dos quais resultam os parâmetros de mercado" (Clemente e Welters, 2007).

2 Todavia, ao longo dos anos esses parâmetros foram sendo considerados nos modelos empíricos conforme as fórmulas seguintes mostram.
} 
Assumindo que a utilidade marginal da renda é positiva, é possível deduzir a partir das Equações (1) e (2) que $\frac{\partial \mathrm{U}_{\mathrm{i}}^{\mathrm{E}}}{\partial \mathrm{Pr}_{\mathrm{i}}}<0, \frac{\partial U_{i}^{E}}{\partial P u_{i}}<0$. Isso implica que um aumento em $\operatorname{Pr}_{\mathrm{i}}$ ou $\mathrm{Pu}_{\mathrm{i}}$ afetaria negativamente a utilidade esperada de um crime, sendo assim, a oferta de crimes seria reduzida seja por um aumento na probabilidade de punição ou pelo aumento em si da punição. Isto é, assume-se que $\frac{\partial \mathrm{O}_{i}}{\partial \mathrm{Pr}_{\mathrm{i}}}<0 \mathrm{e} \frac{\partial O_{i}}{\partial P u_{i}}<0$. Caso o agente fosse avesso ao risco, incrementos em $\mathrm{Pu}_{\mathrm{i}}$ implicariam uma redução acentuada na oferta de crimes.

O efeito dos demais parâmetros na Equação (1) também pode ser previsto. Em caso de maiores retornos em atividades no mercado legal, o custo de oportunidade do crime aumenta implicando em redução do incentivo à prática ilegal. Aumento no custo de planejamento do crime também afeta negativamente a oferta e o benefício líquido do ato ilícito. Isto é, admite-se que $\frac{\partial \mathrm{O}_{i}}{\partial W_{i}}<0$ e $\frac{\partial O_{i}}{\partial C_{i}}<0$.

A oferta de mercado de crimes é dada pelo somatório das ofertas individuais $\left(\mathrm{O}_{\mathrm{i}}\right)$ sendo definida por:

$$
\mathrm{O}^{s}=\mathrm{O}^{s}(\mathrm{~B}, \mathrm{C}, \mathrm{M}, \mathrm{W}, \mathrm{Pr}, \mathrm{Pu})=\sum_{\mathrm{i}=1}^{\mathrm{n}} \mathrm{O}_{\mathrm{i}}
$$

É admitido também que a sociedade possui uma função que representa sua perda social dada por:

$$
\mathrm{L}=(\mathrm{D}, \mathrm{C}, \mathrm{S}, \mathrm{O})
$$

em que $\mathrm{D}$ define os danos sociais causados, $\mathrm{C}$ os custos de combate à atividade criminosa, $\mathrm{S}$ é o custo social por crime sofrido e $\mathrm{O}$ representa o nível de atividade criminal. Admite-se que $\frac{\partial \mathrm{L}}{\partial D}>0, \frac{\partial \mathrm{L}}{\partial C}<0$ e $\frac{\partial \mathrm{L}}{\partial S}>0$.

É razoável também pressupor que a função que define a perda social seja análoga a função de perda total social em termos de renda real de crimes, condenações e punições dada por:

$$
\mathrm{L}=\mathrm{D}(\mathrm{O})+\mathrm{C}\left(\mathrm{P}_{\mathrm{R}}, \mathrm{O}\right)+\mathrm{S}\left(\mathrm{P}_{\mathrm{R}}\right)(\mathrm{O})
$$

em que $\mathrm{S}$ é a perda por crime punida e $\left(\mathrm{P}_{\mathrm{R}}\right)(\mathrm{O})$ é a quantidade de crimes punidos. Dessa forma, o termo $\mathrm{S}\left(\mathrm{P}_{\mathrm{R}}\right)(\mathrm{O})$ representa a perda social total de punições (SANTOS e KASSOUF, 2007).

O modelo ${ }^{3}$ agregado proposto por Oliveira (2008) indica que o indivíduo cometerá algum crime quando:

$$
\mathrm{B}_{\mathrm{I}}>\mathrm{C}_{\mathrm{I}}+\mathrm{M}_{\mathrm{I}}+\mathrm{W}_{\mathrm{I}}+\mathrm{P}_{\mathrm{R}}\left(\mathrm{P}_{\mathrm{U}}\right)
$$

A equação (1) também pode ser reescrita em outra forma onde relaciona o retorno líquido e benefícios e custos associados à atividade criminosa, tal que:

\footnotetext{
${ }^{3}$ As definições dos termos são as mesmas já descritas na Equação 1.
} 


$$
\mathrm{R}_{\mathrm{L}}=\mathrm{B}_{\mathrm{I}}-\left[\mathrm{C}_{\mathrm{I}}+\mathrm{W}_{\mathrm{I}}+\mathrm{P}_{\mathrm{R}}\left(\mathrm{P}_{\mathrm{U}}\right)\right]
$$

Dito isso, sabemos que a moral pode atuar com uma fronteira entre cometer ou não um crime, então chegamos às relações que determinam a opção do indivíduo pela atividade legal ou ilegal. $\mathrm{O}$ indivíduo cometerá um crime se:

$$
\mathrm{R}_{\mathrm{L}} \geq \mathrm{M}_{\mathrm{I}} \text { ou } \mathrm{B}_{\mathrm{I}}-\left[\mathrm{C}_{\mathrm{I}}+\mathrm{W}_{\mathrm{I}}+\mathrm{P}_{\mathrm{R}}\left(\mathrm{P}_{\mathrm{U}}\right)\right] \geq \mathrm{M}_{\mathrm{I}}
$$

O indivíduo não cometerá um crime se:

$$
\mathrm{R}_{\mathrm{L}} \leq \mathrm{M}_{\mathrm{I}} \text { ou } \mathrm{B}_{\mathrm{I}}-\left[\mathrm{C}_{\mathrm{I}}+\mathrm{W}_{\mathrm{I}}+\mathrm{P}_{\mathrm{R}}\left(\mathrm{P}_{\mathrm{U}}\right)\right] \leq \mathrm{M}_{\mathrm{I}}
$$

Franco (2016) inclui ao modelo propriedades intrínsecas que são determinadas a partir da trajetória vívida e que desempenham papel importante nas decisões que levam o indivíduo a cometer um ato ilícito. Essa variável é descrita por X. Além disso, temos que todas essas variáveis citadas ainda são influenciadas de alguma maneira pelo meio no qual os indivíduos inserem-se. E assim, tais impactos serão representados por Z. Outro ponto importante é que a estrutura social, demográfica e jurídica do local em que os indivíduos residem é um macrossistema e será ilustrado por Y.

Destarte, admitindo que o benefício oriundo do crime se relaciona negativamente com a quantia de crimes cometidos, representado por Q, então, em equilíbrio podemos descrever essa relação conforme:

$$
\mathrm{B}(\mathrm{Y}, \mathrm{Q})=\mathrm{C}(\mathrm{X}, \mathrm{Z}(\mathrm{Y}))+\mathrm{M}(\mathrm{X}, \mathrm{Z}(\mathrm{Y}))+\mathrm{W}(\mathrm{X}, \mathrm{Z}(\mathrm{Y}))+\mathrm{P}_{\mathrm{R}}(\mathrm{Y}) \mathrm{P}_{\mathrm{U}}(\mathrm{X}, \mathrm{Z}(\mathrm{Y}))
$$

Efetuando a diferenciação na equação (9) é possível definir de que maneira os elementos locais interagem com a criminalidade a seguir pela equação (10):

$$
\begin{gathered}
\frac{\partial Q}{\partial \mathrm{Y}}=\frac{\left(\mathrm{W}_{\mathrm{Z}}+\mathrm{M}_{\mathrm{Z}}+\mathrm{C}_{\mathrm{Z}}+\mathrm{P} \cdot \mathrm{Pu}_{\mathrm{Z}}\right) \mathrm{Z}^{\prime}(\mathrm{Y})}{\mathrm{B}_{\mathrm{Q}}}+\frac{\left(\mathrm{W}_{\mathrm{X}}+\mathrm{M}_{\mathrm{X}}+\mathrm{C}_{\mathrm{X}}+\mathrm{P} \cdot \mathrm{PuX} \mathrm{X}_{\mathrm{X}}\right) \frac{\mathrm{dX}}{\mathrm{dY}}}{\mathrm{B}_{\mathrm{Q}}} \\
+\frac{\left(\mathrm{P}^{\prime}(\mathrm{Y})\left(\mathrm{P}_{\mathrm{U}}\right)-\mathrm{B}_{\mathrm{Y}}\right)}{\mathrm{B}_{\mathrm{Q}}}
\end{gathered}
$$

Sendo assim, a quantidade média $(\overline{\mathbf{Q}})$ de crimes em uma cidade qualquer está intimamente associada a suas particularidades locais descritas por (Y). Tais características possuem implicações na probabilidade de punição ao indivíduo, sendo representado pelo termo $\frac{\mathbf{P}^{\prime}(\mathbf{Y})\left(\mathbf{P}_{\mathbf{U}}\right)}{\mathbf{B}_{\mathbf{Q}}}$ e, portanto, modificam o retorno do crime cometido, descrito pelo termo $-\frac{\mathbf{B}_{\mathbf{Y}}}{\mathbf{B}_{\mathbf{Q}}}$. Ao mesmo tempo, essas particularidades acabam por impactar o ambiente no qual o agente se insere, com isso, os custos de planejamento também são afetados por elementos endógenos, descritos pelo termo $\frac{\left(\mathbf{W}_{\mathbf{Z}}+\mathbf{M}_{\mathbf{Z}}+\mathbf{C}_{\mathbf{Z}}+\mathbf{P . P} \mathbf{P u}_{\mathbf{Z}}\right) \mathbf{Z}^{\prime}(\mathbf{Y})}{\mathbf{B}_{\mathbf{Q}}}$. Já em relação aos atributos intrínsecos aos agentes exógenos, tem-se o seguinte termo $\frac{\left(\mathbf{W}_{\mathbf{X}}+\mathbf{M}_{\mathbf{X}}+\mathbf{C}_{\mathbf{X}}+\mathbf{P} \cdot \mathbf{P u X _ { X }}\right) \frac{\mathrm{dX}}{\mathrm{d} \mathbf{Y}}}{\mathbf{B}_{\mathbf{Q}}}$. 
Com isso, podemos analisar e debater a criminalidade a partir desse modelo sob quatro perspectivas explicativas, a saber: o efeito das características das cidades acerca do retorno do crime e sua probabilidade de ser punido; e por meio de fatores exógenos e endógenos.

Resumidamente, a estrutura do modelo teórico de Becker visa permitir a compreensão comportamental da atividade criminosa a partir da subdivisão em cinco categorias:

I. A função de oferta agregada de crimes.

II. Os custos sociais da atividade criminosa.

III. O custo de prender e condenar.

IV. Punições.

V. Condições de otimização (BECKER, 1968).

O principal mérito decorrente de sua contribuição teórica é de seu modelo ser o único disponível no campo da Economia do Crime em seu entendimento enquanto problema social. Tal modelo analítico é formulado em direção a estabelecer o menor prejuízo líquido oriundo da violência, bem como seu custo na tentativa de inibir o ato criminoso dado que o crime implica em externalidades negativas à sociedade. Como é evidente, o modelo teórico desenvolvido é elaborado num contexto abstrato e estático (ceteris paribus), logo, indicadores sociais de diversas naturezas são importantíssimos para a compreensão do crime sob o olhar econômico (CLEMENTE e WELTERS, 2017).

Contrapondo o modelo da "escolha racional", os criminologistas James Wilson e Richard Herrnstein (1985) colocam em xeque a premissa da qual o indivíduo se depara com uma questão dicotômica entre atuar ou não no mercado do crime. Segundo eles, o modelo de Becker (1968) desconsidera a possibilidade de o indivíduo atuar simultaneamente entre os dois mercados. Sendo assim, poderia não existir uma fronteira bem definida entre as atividades legal e ilegal.

Acerca da construção moral do agente, que é desenvolvida ao longo de sua vida a partir de suas experiências e relações pessoais, o ambiente socioeconômico é relevante ao indivíduo na explicação de sua formação como parte de uma sociedade. A conhecida abordagem ecológica proposta por Brofenbrenner (1979) foi apropriada aos modelos de análise do crime.

O economista Isaac Ehrlich (1973) objetivou apresentar as implicações sobre o nível de renda, do desemprego e da educação de determinada localidade como um fator atrativo para que o indivíduo opte pelo ato criminoso. Seus estudos o fizeram concluir que o patamar de renda apresentado por certa comunidade eleva as possibilidades de delitos contra a propriedade devido aos retornos pela atividade criminosa elevarem-se. $\mathrm{O}$ desemprego, por sua vez, mostrou-se menos influente no que tange a determinação do crime, contudo, ainda assim é relevante para instigar a atitude criminal.

Tanto para Becker quanto para Ehrlich, a punição representa uma das variáveis centrais para a contenção da criminalidade. No âmbito da punição, podemos distinguir dois efeitos sobre o crime: o efeito de incapacitação que consiste no fato de que o 
criminoso ao estar condenado e preso, o impossibilite de vir a cometer crimes durante este período. $\mathrm{O}$ segundo seria o efeito dissuasão que, após efetuar a condenação de um criminoso, sua punição serve como uma espécie de sinalização para potenciais criminosos que, caso pretendam cometer crimes, também serão condenados e presos.

\section{Revisão Bibliográfica}

No Brasil por muito as investigações econômicas ficaram, de certa forma, restritas a fenômenos macroeconômicos, enquanto temas que dizem respeito ao desenvolvimento da vida do cidadão ficaram em segundo plano. Todavia, a Ciência Econômica gradativamente vem se firmando cada vez mais em temas relacionados à Economia Social, em especial ao tocante da criminalidade. Porém, um dos maiores empecilhos ao avanço dos estudos nacionais nesta temática se dá em virtude da considerável escassez de séries estatísticas robustas. Dessa forma, em função de melhor acesso a dados, a maior parte das pesquisas brasileiras utiliza dados estaduais e municipais, salvo é claro alguns outros trabalhos que dispõem de microdados coletados diretamente nos sistemas carcerários.

Um estudo recente desenvolvido por Carrets et al (2018) buscou examinar os padrões espaciais da Taxa de Homicídio, Taxa de Roubos e Taxa de Roubos de Veículos para o Rio Grande do Sul nos anos de 2005, 2010 e 2015 com base na Análise Exploratória de Dados Espaciais. Com isso, foi constatado que os crimes contra pessoa (Homicidios) possuem uma autocorrelação espacial mais significativa do que os crimes de caráter econômico (Roubos e Roubos de Veículos).

No trabalho realizado por Oliveira et al (2017), foi aplicada a metodologia do Índice Geral de Criminalidade (IGCrime Bayesiano) nos municípios gaúchos e se concluiu que aqueles mais populosos, localizados na Região Metropolitana de Porto Alegre, apresentaram os níveis mais elevados de criminalidade. Ainda, foi observado que a criminalidade estaria migrando rumo ao interior do Rio Grande do Sul.

As regiões que possuem melhores índices de desenvolvimento na área da saúde normalmente apresentam menores taxas de crimes e isso se dá em virtude do acesso a serviços de saúde estarem atrelados a outras questões providenciais como educação e habitação. No Rio Grande do Sul, os locais que dispõem de melhores condições de acesso à saúde apresentam melhores indicadores de criminalidade (PINTO ET AL, 2016).

Em Santos e Santos (2011) foi testada a hipótese de convergência da taxa de crimes no território brasileiro, ou seja, indagado se no futuro a criminalidade atingiria taxas em patamares similares e, dessa forma, não haveria diferença significativa em termos de segurança ao longo do território. Também foi aplicado o coeficiente $I$ de Moran para constatar autocorrelação espacial entre as microrregiões do país. Dessa forma, os autores concluíram que, caso as condições permanecessem iguais ao longo dos anos, é possível que as diferenças na ocorrência de crimes entre as microrregiões seriam reduzidas, bem como seriam acompanhadas por um aumento na taxa média de crimes. 
Santos e Kassouf (2011) desenvolveram um estudo onde buscaram relacionar desemprego, eficiência policial e a implementação do "Estatuto do Desarmamento" como determinantes para as quedas acentuadas da taxa de criminalidade na cidade de São Paulo. A taxa de desemprego foi usada com o intuito de refletir a conjuntura do mercado de trabalho da cidade de São Paulo. Com relação a eficiência policial, atribuíram algumas variáveis como proxies da atividade policial, por exemplo, as prisões realizadas e armas de fogo apreendidas, entre outras. Assim, os efeitos oriundos da efetivação do "Estatuto do Desarmamento" mostraram-se estatisticamente significativas na média de longo prazo das taxas de crimes na cidade de São Paulo. As implicações desse estudo também corroboram com as hipóteses de que apreensões de armas de fogo e prisões realizadas apresentam efeitos negativos sobre a criminalidade. A taxa de desemprego, por sua vez, apresentou resultado positivo, embora esse resultado não seja um consenso na literatura.

Zaluar (2010), por sua vez, acrescenta que existem evidências descritivas sobre a cultura dos povos na América Latina que afirmam que todas as atividades ilícitas que visam à manutenção e disseminação dos empreendimentos ilegais do tráfico concebem a maior contribuição na expansão dos crimes de caráter mais violento. Além disso, outra constatação afirma que a principal distinção entre as vizinhanças pobres e ricas se apresenta no âmbito do nível de denúncias sobre os crimes cometidos, mesmo em localidades com indicadores de criminalidade semelhantes.

Já Oliveira (2008) ressalta o papel da desigualdade de renda e das aglomerações urbanas como fatores que potencializam a criminalidade em cidades no Rio Grande Sul por meio de uma análise espacial do crime. Ele conclui que os benefícios do crime e custos de oportunidade são separados, com isso, afirma que o crescimento econômico por si só não afeta diretamente a criminalidade, pois caso haja melhora de renda nas camadas mais pobres, naturalmente a criminalidade tende a diminuir.

No estudo feito por Brunet et al (2008) chegou-se a um conjunto de parâmetros que apresentaram correlação positiva com a violência na Região Metropolitana de Porto Alegre, a saber: densidade populacional; renda; educação; e, principalmente, mulheres responsáveis pelo domicílio. Essa correlação pode ser explicada, no caso da densidade populacional, pelas teorias da anomia e situacional do crime; na renda, pelas teorias econômica e situacional do crime; na educação, pela sua elevada correlação com a renda, e no de mulheres responsáveis pelo domicílio, pela teoria da desorganização social. Além disso, o estudo ressalta a importância da interpretação espacial do crime para que assim as ações de políticas públicas possam ser executadas em localidades específicas.

Hartung e Pessoa (2007) apresentaram algumas constatações interessantes em relação ao que costumeiramente é abordado na literatura brasileira a partir de uma análise em cidades paulistanas. Em seus estudos buscaram inserir na análise econômica do crime variáveis demográficas como taxa de fecundidade, percentual de crianças criadas somente pela mãe, percentual de crianças nascidas de mãe adolescente, etc. e que, além de afetarem de maneira significativa as taxas de criminalidade, o seu impacto de fato só viria ocorrer num período relativamente distante. 
Segundo Oliveira (2005), as cidades brasileiras na década de 1990, com densidade populacional mais expressiva e desenvolvidas, tendem a gerar incentivos a atividade criminosa cujas cidades pequenas não podem oferecer. Além de gerar incentivos positivos à criminalidade, existem fatores do ambiente social que corroboram para a atividade ilícita, pois este é relevante na formação dos costumes, histórico e valores morais do indivíduo. Portanto, resultados obtidos a partir da estimação realizada concluíram que o tamanho das cidades é significativo na explicação da criminalidade.

Para Mendonça (2002) o consumo de um indivíduo é referenciado de maneira imposta e exógena a ele pelos demais agentes numa sociedade. Sendo assim, a forma como o agente se enxerga em relação ao todo é um fator gerador da atividade ilícita. Em outras palavras, o sentimento de insatisfação decorrente de sua impossibilidade de acesso a determinado consumo e status sociais o afeta emocionalmente a ponto de estar propenso a optar pelo mercado do crime. Os dados utilizados em sua análise foram entre os anos de 1985-1995 e foram modelados a partir de dados em painel dos estados brasileiros. Os resultados indicaram que o grau de insatisfação do indivíduo reduz o retorno exigido como critério de decisão para cometer um crime.

Schaefer e Shikida (2001) realizaram um estudo de campo aplicado em um presídio na cidade de Toledo (PR) e chegaram a duas conclusões complementares. A primeira é que as principais motivações para os detentos optarem pela atividade foram: a persuasão de amigos; necessidade de contribuir com o orçamento familiar; e a possibilidade de "ganho fácil". A segunda foi que o descuido e eficiência policial são os principais determinantes para o insucesso na atividade criminosa.

Conforme seus resultados, as conclusões apresentam um caráter intrigante em alguns pontos; o primeiro, pois vai de encontro ao que comumente é atribuído nos estudos nacionais de que a concentração de renda e o PIB são relevantes na explicação das altas taxas de criminalidade brasileira; segundo que no caso de crimes violentos como o homicídio, nenhuma das variáveis econômicas apresentou significância estatística ao passo que as variáveis demográficas mostraram uma relação positiva com a criminalidade nos anos futuros e; que no curto prazo, somente a atuação do Estado seria capaz de afetar essa categoria de crime por meio de mecanismos que pudessem elevar a possibilidade de prisão.

Por fim, existem inúmeras questões que se mostraram relevantes no entendimento mais aprofundado dos determinantes e condicionantes do ato criminoso que transitam entre questões intrínsecas ao indivíduo, fatores sociais e especificidades do ambiente onde estão inseridos, efetividade das instituições públicas etc. A questão fundamental é que o campo da Economia do Crime é complexo e ainda demanda estudos com um enfoque complementar a categorias subjetivas do indivíduo além dos aspectos econômicos, ou seja, depende da atuação de outras ciências como Psicologia, Sociologia, Criminologia etc.

\section{Metodologia}


Nessa seção são abordadas as ferramentas necessárias para as estimações, bem como a base de dados e os componentes relevantes para a realização da pesquisa.

\section{a. Autocorrelação Espacial Local Univariada}

Inicialmente em um estudo de análise exploratória de dados espaciais deve-se conferir a hipótese base da qual os dados espaciais são distribuídos aleatoriamente, ou seja, que os valores de variáveis de uma região não são dependentes de valores de localidades vizinhas.

Neste estudo a estatística de correlação espacial utilizada será o $I$ de Moran. O coeficiente de correlação espacial de Moran é dado pela autocovariância em forma de produto cruzado. $\mathrm{O}$ mesmo pode ser definido algebricamente da seguinte maneira:

$$
\mathrm{I}=\left(\frac{\mathrm{n}}{\mathrm{S}_{0}}\right) \times \frac{\sum_{\mathrm{i}} \sum_{\mathrm{j}} \mathrm{w}_{\mathrm{ij}} \mathrm{z}_{\mathrm{i}} \mathrm{z}_{\mathrm{j}}}{\sum_{\mathrm{i}=1}^{\mathrm{n}} \mathrm{z}_{\mathrm{i}}^{2}}
$$

Ou também em sua forma matricial:

$$
\mathrm{I}=\left(\frac{\mathrm{n}}{\mathrm{S}_{0}}\right) \times \frac{\mathrm{z}^{\prime} \mathrm{W}_{\mathrm{z}}}{\mathrm{z}^{\prime} \mathrm{z}}
$$

posto que $\mathrm{n}$ é o número de regiões, $\mathrm{z}$ define os valores das variáveis de interesse padronizada, $\mathrm{W}_{\mathrm{z}}$ representa os valores médios da variável de interesse padronizada nos vizinhos, determinados conforme uma matriz de ponderação espacial W. Os elementos dessa matriz, correspondente à região i e à região $\mathrm{j}$, são caracterizados como sendo $\mathrm{w}_{\mathrm{ij}}$. Já $\mathrm{S}_{0}$ é igual ao operador $\Sigma \Sigma \mathrm{w}_{\mathrm{ij}}$.

Como já foi dito, a hipótese testada é a da aleatoriedade espacial. Dessa forma, é sabido que o $I$ de Moran tem um valor esperado dado pela seguinte expressão:

$$
\mathrm{E}(\mathrm{I})=-\frac{1}{(\mathrm{n}-1)}
$$

esse indicador representa o valor que seria obtido caso não houvesse padrão espacial nos dados em questão.

A respeito da interpretação dos resultados existem algumas sutilezas. Quando a autocorrelação espacial é positiva, diz-se que existe similaridade entre os valores do parâmetro estudado e da localização do mesmo. Em caso de um coeficiente de autocorrelação espacial negativo, diz que há dissimilaridade entre os valores e a localização espacial. Em outras palavras, no primeiro caso valores altos da variável estudada, em geral, estão agrupados com outras regiões de valores altos. No caso de valores baixos o raciocínio é o mesmo. Já na dissimilaridade, temos que localidades de valores baixos, em geral, estão agrupadas com regiões de valores altos para o mesmo atributo. 
No que tange a significância estatística é aceito a premissa de que o coeficiente $\mathrm{Z}(I)$ segue distribuição normal com média zero e variância unitária. Sendo exposta abaixo:

$$
\mathrm{Z}(\mathrm{I})=\left(\overline{\mathrm{X}}, \sigma^{2}\right)
$$

\section{b. Matriz de Pesos Espaciais (W)}

Conforme Almeida (2012) uma matriz de ponderação espacial baseia-se no conceito de contiguidade (vizinhança) das regiões observadas. Os pesos espaciais $w_{i j}$ representam a intensidade de conexão entre as regiões a partir de um determinado critério de proximidade, mostrando assim, a influência da região $j$ sobre a região $i$. Sendo assim, a matriz $W$ é importante para realizar a ponderação da influência que as regiões exercem entre si.

A matriz de pesos é construída a partir de determinado conceito de vizinhança fundamentado na contiguidade, em que regiões são consideradas vizinhas, caso elas possuam fronteiras físicas em comum. Dito de outra forma, é que quando regiões são contíguas elas possuem uma maior interação espacial.

Dessa forma, a matriz indica qual modelo de fronteira será adotado na análise. Existem dois tipos principais de matriz de pesos, a saber: Rainha (Queen) e Torre (Rook). Uma matriz de pesos contígua é dita do tipo Rainha (Queen) se, além considerar as fronteiras físicas, também levar em consideração os vértices como contíguos. Caso somente as regiões que possuem fronteiras físicas são consideradas contíguas, então essa matriz de pesos é chamada de tipo Torre (Rook). Neste trabalho optou-se por utilizar o padrão Rainha (Queen) para a matriz de pesos espaciais, em que a ordem de vizinhança é igual a um. Ou seja, todas aquelas regiões que possuam qualquer tipo de fronteira com unidade analisada, conforme a Figura 1.

\section{Figura 1 - Convenção "Rainha" de Contiguidade}

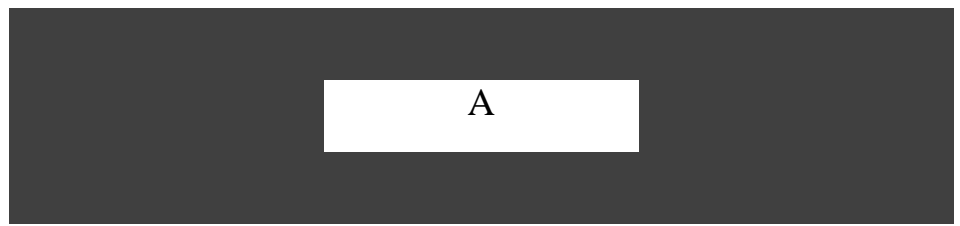

Fonte: Almeida (2012, p.77).

c. Diagrama de Dispersão de Moran

Este diagrama exibe a defasagem espacial do parâmetro observado no eixo vertical e o valor do parâmetro de interesse no eixo horizontal. Vale destacar que tanto a variável de interesse (y) e sua defasagem espacial $\left(\mathrm{W}_{\mathrm{y}}\right)$ serão padronizadas com base na distribuição normal, $\operatorname{logo}$, sendo transformadas em $\mathrm{z} \mathrm{e} \mathrm{W}_{\mathrm{z}}$. Um gráfico ilustra os pontos observados dispersos das regiões com referência à declividade da reta de regressão. 
Dito de outra maneira, o coeficiente de Moran nada mais é do que a declividade da reta estimada por mínimos quadrados ordinários simples (MQO). Formalmente:

$$
\mathrm{W}_{\mathrm{z}}=\alpha+\beta \mathrm{z}+\varepsilon
$$

Com isso, o coeficiente de I de Moran é compreendido como sendo o ângulo da reta de regressão (15) representado pela seguinte expressão:

$$
\widehat{\beta}=\mathrm{I}=\frac{\mathrm{z}^{\prime} \mathrm{W}_{\mathrm{z}}}{\mathrm{z}^{\prime} \mathrm{z}}
$$

O diagrama de Moran é dividido em quatro quadrantes. Na diagonal principal temos a associação linear do tipo Alto-Alto (AA) e Baixo-Baixo (BB), valores próximos de +1 que indicam autocorrelação espacial positiva. Na diagonal secundária temos AltoBaixo (AB) e Baixo-Alto (BA), valores próximos de -1 , que indicam autocorrelação negativa. Valores próximos de zero indicam que a unidade não está significativamente associada espacialmente aos seus vizinhos.

\section{d. Base de dados}

As informações analisadas no estudo referem-se às taxas de crime a cada cem mil habitantes ${ }^{4}$ nos $496^{5}$ municípios do estado gaúcho, disponibilizadas pela Secretaria de Segurança Pública do Rio Grande do Sul (SSP-RS). A SSP-RS disponibiliza tais informações a partir de 2002 e, assim, formam selecionadas para este estudo os anos de 2002, 2010 e 2018, contemplando todo o período de informações disponíveis, com intervalos de 8 anos. Foram considerados os crimes de homicídio, tráfico de entorpecentes e roubos, descritos na Tabela 1. A taxa de homicídios é comumente utilizada na literatura de economia do crime, pois está menos suscetível ao sub-registro (SANTOS e SANTOS, 2011). Já os crimes de tráfico de entorpecentes e roubos são, geralmente, por motivação financeira e correspondem a uma parcela expressiva do total das prisões no Estado do Rio Grande do Sul.

Cabe ainda mencionar que, nesse trabalho em específico, os parâmetros considerados não foram padronizados apesar de o referencial metodológico sugerir a necessidade de padronização. Como foram utilizadas variáveis de mesma natureza (crimes), bem como pela escala das variáveis estarem balanceadas (mesma magnitude), não foi necessário realizar tal padronização.

\section{Quadro 1 - Tipos de Crimes Abordados na Pesquisa.}

\begin{tabular}{|c|l|l|}
\hline \hline Crime & \multicolumn{1}{|c|}{ Descrição } & \multicolumn{1}{|c|}{ Pena } \\
\hline Homicídio doloso & $\begin{array}{l}\text { Ocorre quando uma pessoa mata outra ou tem a intenção } \\
\text { de matar. Previsto no artigo 121, p.1-2 do código penal } \\
\text { brasileiro. }\end{array}$ & $\begin{array}{l}\text { Reclusão, de 6 } \\
\text { a 20 anos }\end{array}$ \\
\hline Tráfico de & Qualquer tipo de movimentação e disposição de drogas & Reclusão, de 5 \\
\hline
\end{tabular}

\footnotetext{
${ }^{4}$ A população utilizada foi coletada no Censo 2010 disponibilizado pelo IBGE.

${ }^{5}$ Foi desconsiderada a cidade de Pinto Bandeira, pois a mesma só foi emancipada em 2012.
} 


\begin{tabular}{|c|l|l|}
\hline entorpecentes & $\begin{array}{l}\text { de um para outro em desacordo com determinação legal. } \\
\text { Previsto no artigo 33 do código penal brasileiro. }\end{array}$ & \\
\hline \multirow{3}{*}{ Roubos } & $\begin{array}{l}\text { Ato de subtrair coisa móvel alheia para si ou para } \\
\text { outrem, mediante grave ameaça ou violência e, depois }\end{array}$ & \\
& $\begin{array}{l}\text { de havê-la, por qualquer meio, reduz a impossibilidade } \\
\text { de resistência. Previsto no artigo 157 do código penal } 4 \text { a } \\
\text { brasileiro. }\end{array}$ & \begin{tabular}{l} 
Re anos \\
\hline
\end{tabular} \\
\hline
\end{tabular}

Fonte: Código Penal Brasileiro. Elaboração própria.

\section{Resultados}

Nesta seção são expostos os principais resultados obtidos e suas interpretações referentes aos anos de 2002, 2010 e 2018 para que se possa observar possíveis deslocamentos da atividade criminosa em busca de melhores oportunidades. Em cada um dos anos citados serão exibidos dois gráficos: um sobre a distribuição espacial de cada crime considerado e outro contendo os clusters de criminalidade.

\section{a. Dependência espacial}

A estatística I de Moran para os municípios gaúchos nos anos de 2002, 2010 e 2018 referente aos três tipos de delitos aqui apresentados (Homicídio, Roubos e Tráfico de Entorpecentes) é condensada na Tabela 1. Observa-se evidências de dependência espacial nas taxas de roubo, uma vez que os valores do coeficiente de I de Moran foram positivos e próximos a 0,2 nos anos analisados. Assim, as cidades que possuem alta (ou baixa) taxa de roubo são vizinhas de outras cidades que também possuem alta (baixa) criminalidade. No caso das taxas de entorpecentes existem evidências de dependência espacial positiva nos anos de 2010 e 2018. Já para as taxas de homicídios, não há evidências de correlação espacial, uma vez que o índice foi próximo a zero.

Tabela 1 - Coeficientes I de Moran para os Anos de 2002, 2010 e 2018.

\begin{tabular}{c|c|c|c}
\hline \hline Anos & Taxa de Homicídio & $\begin{array}{c}\text { Taxa de } \\
\text { Roubos }\end{array}$ & $\begin{array}{c}\text { Taxa de Tráfico de } \\
\text { Entorpecentes }\end{array}$ \\
\hline 2002 & 0,043 & 0,227 & 0,014 \\
\hline 2010 & 0,060 & 0,181 & 0,127 \\
\hline 2018 & 0,051 & 0,241 & 0,172 \\
\hline Média & 0,051 & 0,216 & 0,104 \\
\hline Desvio Padrão & 0,009 & 0,031 & 0,081 \\
\hline \hline
\end{tabular}

Fonte: SSP-RS. Elaboração própria com o software GeoDa 1.14.

A motivação para esse tipo de crime pode ou não ser monetária. Por exemplo, em crimes contra pessoa, a motivação pode ser devido a questões passionais ou de vingança, ou então estar relacionada a outras atividades ilegais que se utilizem dos homicídios como forma de ação. Já os crimes como tráfico e roubos expressam um caráter muito mais econômico, em que os principais benefícios são financeiros e, sendo assim, a 
concentração de riqueza se torna central para que exista agrupamento espacial desses crimes.

Dito isso, então é possível a criação de mapas que exponham as regiões correlacionadas, em que o Quadro 2 apresenta os tipos de associação espacial.

\section{Quadro 2 - Legenda para Leitura dos Mapas de Dependência Espacial ${ }^{6}$}

\begin{tabular}{|c|c|}
\hline \hline Tipo de Associação & Descrição \\
\hline Alto-Alto & Alta criminalidade circundada por alta criminalidade \\
\hline Alto-Baixo & Alta criminalidade circundada por baixa criminalidade \\
\hline Baixo-Alto & Baixa criminalidade circundada por alta criminalidade \\
\hline Baixo-Baixo & Baixa criminalidade circundada por baixa criminalidade \\
\hline Não-significante & Não há associação espacial nessas regiões \\
\hline \hline
\end{tabular}

Fonte: Elaboração própria usando o software GeoDa 1.14.

Para que se identifiquem os padrões espaciais entre as regiões observadas calculam-se as estatísticas locais de autocorrelação espacial (LISA). O mapa de clusters LISA mescla a informação extraída do diagrama de dispersão de Moran juntamente com a informação oriunda do mapa de significância das medidas de associação local (ALMEIDA, 2012).

b. Discussão sobre a taxa de homicídios

Na Figura 2 é possível notar um padrão de distribuição heterogêneo das taxas de homicídio no estado nos três anos analisados. O gradiente de cores varia de acordo com a intensidade de ocorrências, ou seja, quanto mais claro, menor é a taxa de crimes e, quanto mais escuro, maior a taxa de crimes. Esse raciocínio é o mesmo para os mapas dos demais crimes analisados. Os valores que estiverem entre parênteses representam a respectiva taxa de homicídio para determinada cidade.

No ano de 2002, dos municípios com 50 mil habitantes ou mais, as cinco cidades com as maiores taxas de homicídio por cem mil habitantes foram: Alvorada $(38,8)$, Porto Alegre (29,1), Esteio (27,2), São Leopoldo (27,1) e Erechim (27,1). Vale comentar também que cidades com população expressiva como Santa Maria, Pelotas, Gravataí e Rio Grande registraram taxa de homicídios inferior a dez ocorrências por cem mil habitantes.

Em 2010 Alvorada (46,5), Guaíba (31,5), São Leopoldo (31,3), Esteio $(29,7)$ e Sapucaia do Sul $(29,0)$ foram as cinco cidades com a maior taxa dentre aqueles com população superior a 50 mil habitantes. Porto Alegre reduziu sua taxa de 29,1 para 26,0,

\footnotetext{
${ }^{6}$ Indicadores locais construídos sob o critério de contiguidade do tipo "rainha". Todos os clusters são significativos a 95\% para a detecção dos agrupamentos espaciais, bem como seus principais vizinhos.
} 
queda aproximada de $11 \%$. Nesse mesmo ano, São Gabriel $(3,3)$ foi o município que registrou a menor taxa de homicídio. Santa Maria, por sua vez, passou de uma taxa de homicídio de 8,80 para 10,3, aumento na magnitude de $17 \%$.

Já em 2018, Alvorada $(63,4)$ continuou sendo a cidade mais violenta de todo o estado, havendo um aumento considerável na taxa de homicídios, 36,3\% se comparado ao ano de 2010. Após Alvorada (63,4), temos Viamão $(45,1)$, Bento Gonçalves $(39,2)$, Porto Alegre $(32,5)$ e Canoas $(31,8)$ constituindo as cinco cidades com as maiores taxas de homicídios no último ano analisado. Considerando apenas as cidades com população acima de 50 mil habitantes, a taxa média de homicídio desse grupo é de 17,7. O que caracteriza um valor considerável no tocante a criminalidade. Além disso, observa-se que Santa Maria aumentou exponencialmente suas taxas de homicídios. De 2002 para 2018 ocorreu aumento na magnitude de 152\%. Em 2018 a taxa de homicídios em Santa Maria foi de 21,45 casos a cada cem mil habitantes. Se compararmos com Alvorada, a mesma registrou aumento na casa dos 63,4\% no mesmo período, ou seja, a violência em Santa Maria aumentou de maneira muito mais acentuada do que a cidade com a maior taxa de homicídio.

Figura 2 - Distribuição da Taxa de Homicídios nos Anos de 2002, 2010 e 2018

2002

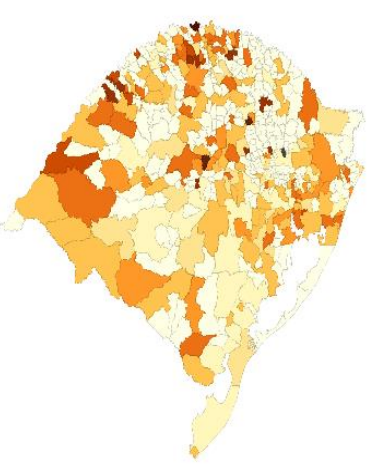

2010

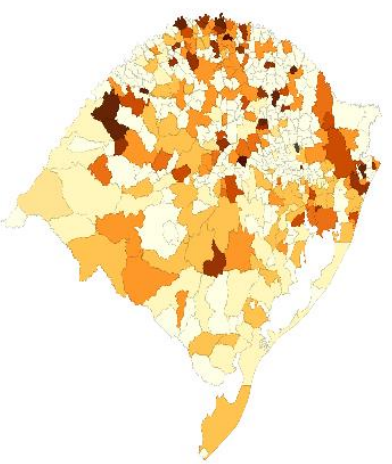

2018

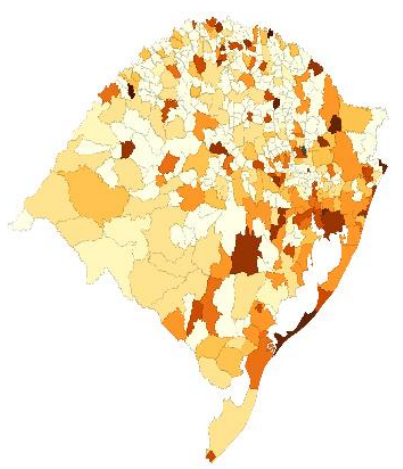

Fonte: Elaboração própria usando o software GeoDa 1.14.

Por mais que existam poucos municípios com elevada taxa de homicídios no interior do estado, eles não são a regra, pois, dado a baixa população residente, qualquer nova ocorrência é suficiente para que sua taxa de crimes seja elevada. Nesse caso podemos citar em 2018, Mariano Moro (90,5), Dezesseis de Novembro $(69,8)$, Monte Alegre dos Campos $(64,5)$.

Na Figura 3 observa-se os clusters de criminalidade referente à taxa de homicídios. Os anos de 2002 e 2010 apresentam padrão semelhante no que se refere ao agrupamento espacial Alto-Alto formado na região Noroeste. Nessa região, em 2002, alguns municípios apresentam esse padrão, a saber: Frederico Westphalen, Erval Seco, Trindade 
do Sul, Campo Novo, Vicente Dutra, Tenente Portela, Planalto, etc. Ainda no Noroeste, pode-se visualizar também alguns outliers espaciais (Baixo-Alto) que circundam esses municípios como: Derrubadas, Palmitinho, Três Passos, Caiçara, São Pedro das Missões, entre outros. Somente quatro cidades da Região Metropolitana de Porto Alegre aparecem no grupo Alto-Alto, e são: Viamão, Capivari do Sul, Barra do Ribeiro e Santo Antônio da Patrulha. Outro cluster relevante é aquele mais localizado entre as fronteiras das regiões Noroeste, Nordeste e Centro Oriental destacados pela cor azul escuro. Nesse grupo, destacam as seguintes cidades: Westfália, Campestre da Serra, Santa Cecília do Sul, Água Santa, Dois Lajeados, Arroio do Meio, Nova Pádua etc.

Em 2010 os clusters Alto-Alto se localizam fortemente na região Noroeste e em parte no Litoral do Rio Grande do Sul. Na primeira região localizam-se os seguintes municípios: Frederico Westphalen, Vicente Dutra, Erval Seco, Tenente Portela, Trindade do Sul, Planalto, Sarandi, entre outros. Já no Litoral, estão os seguintes: Torres, Tramandaí, Capão da Canoa e Palmares do Sul. Há também um foco de cidades do tipo Baixo-Baixo mais localizado na região Centro Oriental, a saber: União da Serra, Nova Pádua, Forquetinha, Capitão, Santa Tereza, Westfália, entre outras.

Para 2018, a configuração se altera de maneira significativa. Como se pode ver, o polo onde se localizam municípios de agrupamento Alto-Alto fica na Região Metropolitana de Porto Alegre (RMPA). Nesse sentido, vale pontuar que de 2010 a 2018 os homicídios no estado aumentaram $26,4 \%$. Além disso, considerando as dez maiores populações do estado, em 2010 a taxa média de homicídio era de 18,9, enquanto em 2018, essa taxa média foi de 26,1, ou seja, aumento de 38\%. Então, é possível que esse aumento expressivo tenha sido impulsionado por essas cidades maiores, em que boa parte delas faz parte da RMPA. Isso pode ser justificado pela literatura teórica que aponta que centros urbanos e cidades de maior porte facilitam o intercâmbio de informações, a organização e a logística envolvida nas atividades ilícitas, bem como dificultam a identificação do agente criminoso (SANTOS E SANTOS, 2011).

Dito isso, algumas das cidades do tipo Alto-Alto merecem destaque, sendo elas: Viamão, Gravataí, Parobé, Tramandaí, Cachoeirinha, Capivari do Sul etc. Outro destaque em 2018 se dá pelo aumento do número de clusters espaciais de tipo Alto-Baixo, como em: Cruz Alta, Santa Maria, Passo Fundo, Lagoa Vermelha, São Miguel das Missões, Bento Gonçalves, entre outros.

Figura 3 - Clusters para a Taxa de Homicídios nos Anos de 2002, 2010 e 2018 2002 2010 2018 

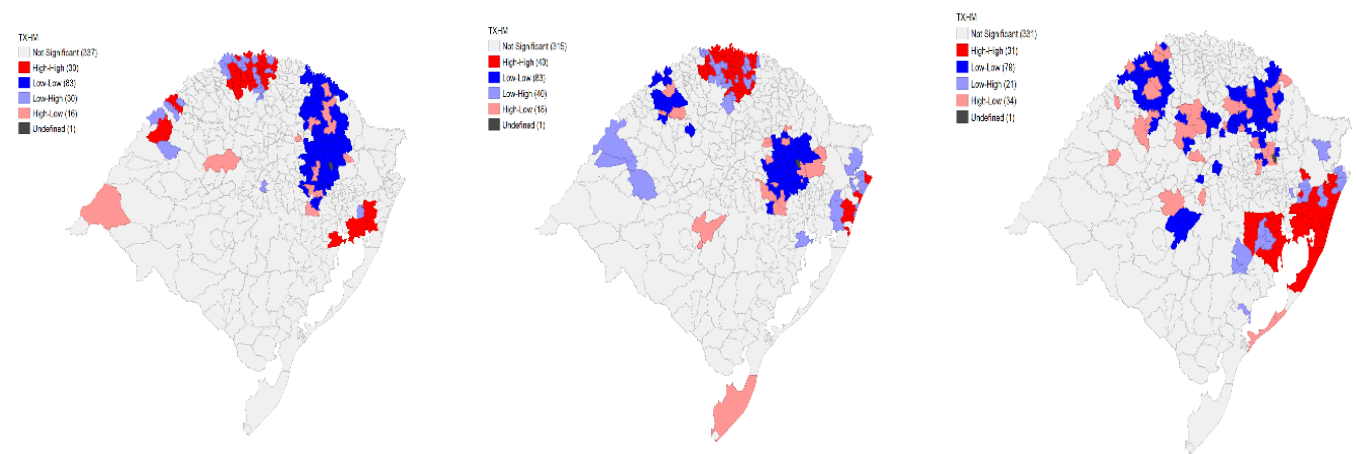

Fonte: Elaboração própria usando o software GeoDa 1.14.

Dessa maneira, nota-se que a RMPA vem ganhando destaque no tocante a criminalidade com o passar dos anos e cada vez mais cidades estão se inserindo no grupo Alto-Alto, colaborando assim, para uma maior vulnerabilidade da região.

c. Discussão sobre taxa de roubos

Os roubos são um dos crimes mais volumosos em termos de prisões geradas no Rio Grande do Sul. Segundo dados fornecidos pelo Departamento Penitenciário Nacional (DEPEN) em 2017 os roubos representaram 28,39\% de todas as prisões realizadas até junho daquele ano em todo o estado. Também, se considerado somente os crimes contra o patrimônio, esse crime corresponde a $60,28 \%$ de todas as prisões geradas pelo estado gaúcho.

Na Figura 4 observa-se a distribuição espacial referente à taxa de roubo. Assim como na taxa de homicídios, os valores entre parênteses descrevem a taxa de roubos para o respectivo município. Essa taxa considera a quantidade de ocorrências de roubo a cada cem mil habitantes.

Dentre as cidades com mais de 50 mil habitantes, observamos que Porto Alegre (1.441,2), Guaíba (1.402,3), São Leopoldo (1.115,4), Alvorada (1.097,2) e Canoas $(1.010,4)$ apresentaram as maiores taxas de roubo no ano de 2002. Santa Maria $(403,4)$, por sua vez, registrou no ano de 2002 uma taxa abaixo das maiores taxas do estado nesse tipo de crime.

Figura 4 - Distribuição da Taxa de Roubos nos Anos de 2002, 2010 e 2018 2002 2010 2018 

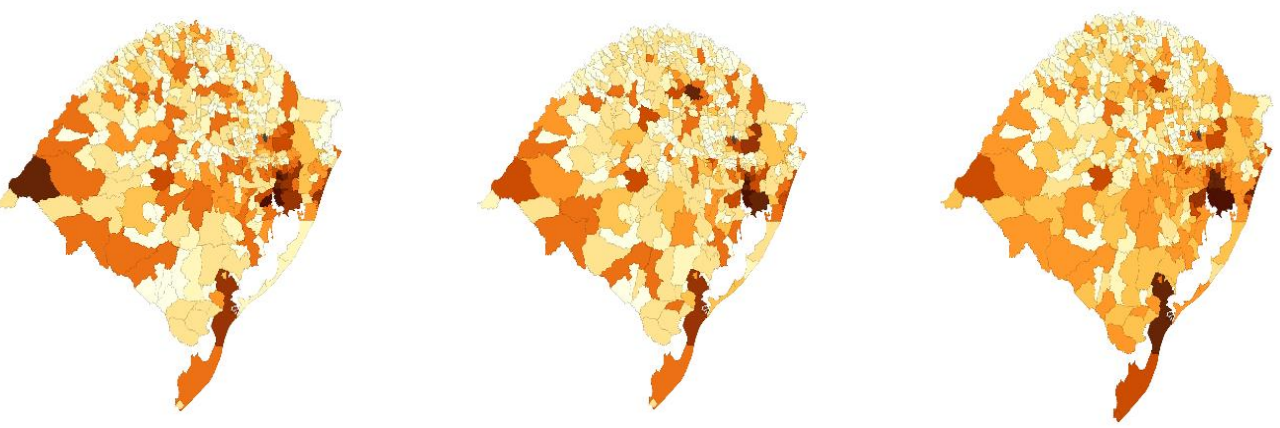

Fonte: Elaboração própria usando o software GeoDa 1.14.

Para o ano de 2010, considerando esse mesmo extrato, Alvorada (1.171,3), Porto Alegre $(1.131,8)$, Sapucaia do Sul $(1.121,0)$ e Esteio $(1.119,4)$ registram as maiores taxas de roubo. Nesse ano, Santa Maria tem taxa de $(467,0)$, com isso, houve um aumento de 15,8\% em relação a 2002. Já em 2018, dentre as maiores taxas aparecem: Porto Alegre $(2.139,0)$, Alvorada (1.824,5), Viamão (1.599,5), Cachoerinha (1.202,3) e Canoas $(1.141,0)$. Entre 2002 e 2018, é possível observar o aumento na taxa média de roubo entre os municípios com população acima de 50 mil habitantes. Em 2002 esse foi 472,9, enquanto em 2018 a taxa média foi de 552,1, ou seja, aumento de $16,7 \%$. Nos municípios menores, em termos de número de habitantes, não houve aumento expressivo.

Em 2002 observa-se na RMPA a maior concentração de agrupamentos de tipo Alto-Alto e uma parcela na Região Nordeste. Esse ano foi o que mais apresentou clusters desse tipo de associação espacial totalizando 56 municípios. Na RMPA merece destaque alguns municípios: Porto Alegre, Canoas, Novo Hamburgo, Gravataí, São Leopoldo, Sapucaia do Sul, Portão, Viamão, Gramado, entre outros. Já mais ao Nordeste destaca-se: Caxias do Sul, Farroupilha e Carlos Barbosa.

No ano de 2010 também se tem a RMPA como polo das associações espaciais do tipo Alto-Alto. Também observa-se que nessa região concentra número razoável de cidade de tipo Baixo-Alto em seu entorno. No grupo Alto-Alto têm-se os municípios a seguir: Porto Alegre, Viamão, Gravataí, São Leopoldo, Sapucaia do Sul, Guaíba, Capivari do Sul, Novo Hamburgo, entre outros. Na circunvizinhança dessa região, as seguintes cidades que apresentaram correlação do tipo Baixo-Alto, foram: Linha Nova, São José do Sul, Lindolfo Collor, Nova Hartz, Três Coroas etc.

Para 2018 os agrupamentos espaciais são semelhantes aos anos anteriores. Os principais clusters do tipo Baixo-Baixo estão localizados entre as regiões Noroeste, Nordeste e em parte na região Central do Rio Grande do Sul. Na primeira região destacam-se os seguintes municípios: Três Passos, Frederico Westphalen, Alecrim, Nonoai, Palmeira das Missões, Santa Rosa entre outros. Na segunda região fazem parte essas cidades: Nova Prata, Nova Pádua, Veranópolis, Antônio Prado, Vista Alegre do Prata etc. E por fim, na Região Central pode-se mencionar alguns municípios, sendo eles: Jaguari, Capão do Cipó, Sobradinho, Boqueirão do Leão, Muçum, entre outros. Dos 
outliers espaciais do tipo Alto-Baixo são passíveis de destaque as cidades de Santa Maria, Cruz Alta, Ijuí, Passo Fundo, Erechim, conforme exibe a Figura 5. O padrão de cores no gráfico segue a seguinte classificação: o vermelho em tom escuro representa alta criminalidade circunvizinha de alta criminalidade; o vermelho claro alta criminalidade circunvizinha por baixa criminalidade; o azul em tom claro baixa criminalidade circunvizinha por alta criminalidade; o azul em tom escuro baixa criminalidade circunvizinha por baixa criminalidade e; a cor branca que não há associação espacial nessas regiões.

No caso dos roubos, observa-se que em todos os anos de análise os agrupamentos de tipo Alto-Alto estiveram concentrados na RMPA, em função da maior geração de riqueza do estado estar localizada nesta região. Em 2015, como exemplo, somente Porto Alegre, Canoas, Gravataí e Novo Hamburgo correspondem a 26,7\% de todo o PIB do estado (FEE, 2017). Como o roubo possui caráter econômico essas localidades representam um atrativo maior para a atividade ilícita.

Figura 5 - Clusters para a Taxa de Roubos nos Anos de 2002, 2010 e 2018

2002

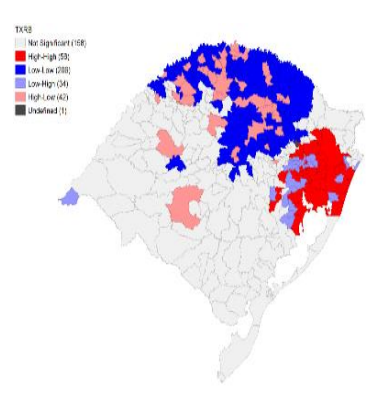

2010

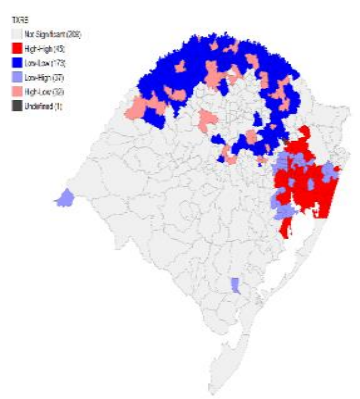

2018

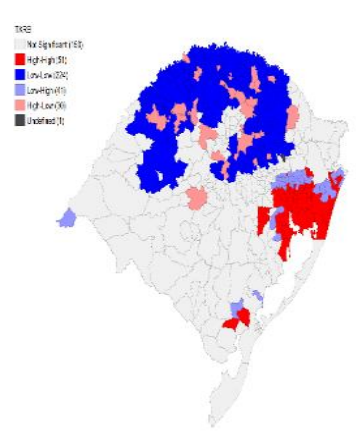

Fonte: Elaboração própria usando o software GeoDa 1.14.

d. Discussão sobre a taxa de tráfico de entorpecentes

Na Figura 6 pode-se observar que o tráfico de entorpecentes vem aumentando e se espalhando por todo o estado com o passar dos anos. O tráfico vem se tornando cada vez mais predominante no Rio Grande do Sul muito em função da atuação de facções regionais, bem como da ação do Primeiro Comando da Capital (PCC) e do Comando Vermelho (CV). Segundo Costa e Adorno (2018), o Rio Grande do Sul ainda é 
majoritariamente dominado por facções regionais ${ }^{7}$, porém, dada a variedade de gangues atuantes, o Estado gaúcho acaba por sofrer com os conflitos entre facções como exemplo, a disputa por territórios e outros crimes que decorrem das atividades ilegais do tráfico de drogas e que a eles estão atrelados, e assim, aprofundando ainda mais a violência nos locais onde atuam.

Em 2002 poucas cidades possuíam elevada taxa de tráfico. Assim como no crime de roubo, a taxa considera a quantidade de ocorrências de tráfico de entorpecentes ajustada a cada cem mil habitantes.

Considerando os municípios com população acima de 50 mil habitantes, aqueles que registraram as maiores taxa são: Cruz Alta (39,8), Porto Alegre (31,2), Lajeado $(30,8)$, Alvorada $(20,4)$ e Montenegro $(20,2)$. Santa Maria, por sua vez, registrou taxa de tráfico de apenas 6,9. Como se pode ver, as taxas mais elevadas estão bem dispersas ao longo do estado no ano em questão, ao passo que nos anos seguintes há uma intensificação das ocorrências por todo estado conforme a Figura 6.

Para 2010 observa-se dispersão com diferenças consideráveis, seja na maneira como se distribuiu ao longo do estado, bem como na magnitude das taxas dos municípios. Nesse ano, as taxas mais elevadas foram: Porto Alegre (178,5), Canoas (103,1), Cruz Alta $(100,3)$, Rio Grande $(91,8)$ e Uruguaiana $(91,7)$. De imediato se observa a discrepância entre as taxas mais elevadas desse ano em relação ao primeiro ano analisado. Porto Alegre, que em 2002 registrou 440 ocorrências de tráfico, saltou para mais de 2.500 em 2010.

Figura 6 - Distribuição da Taxa Tráfico de Drogas nos Anos de 2002, 2010 e 2018

2002

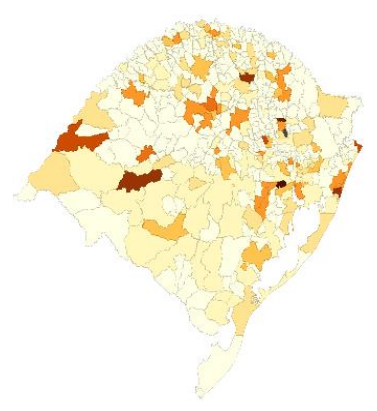

2010

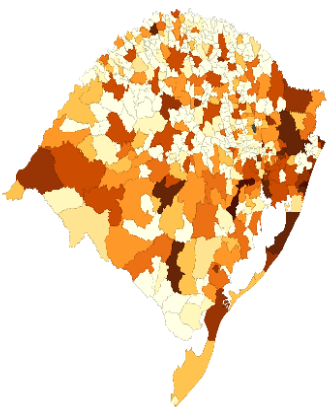

2018

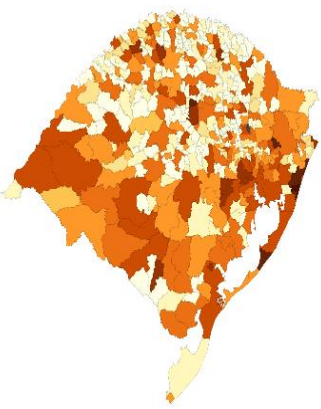

Fonte: Elaboração própria usando o software GeoDa 1.14.

Já em 2018 não houve alteração tão brusca quanto de 2002 para 2010. A taxa média de tráfico em 2002 era 12,3, em 2010 era 60,1 e 2018 foi de 113,9, logo, uma variação positiva de mais de $800 \%$ ao longo dos anos analisados. No ano em questão os

\footnotetext{
${ }^{7}$ As principais facções regionais são: Manos, Balas na Cara, Abertos, Unidos pela Paz, Primeiro Comando do Interior, Os Tauros, Os Brasas.
} 
municípios com as maiores taxas foram: Santa Rosa $(186,6)$, São Gabriel $(175,4)$, Rio Grande $(173,9)$, Lajeado $(172,2)$ e Canoas $(169,2)$.

Portanto, fica claro que o tráfico de drogas vem tomando uma proporção cada vez maior no estado e embora as grandes facções como PCC e CV ainda não possuam participação expressiva no Rio Grande do Sul, ainda assim existe o risco de as facções regionais estabelecerem alianças com as mesmas a fim de aumentar sua influência na criminalidade local.

Para 2002 as aglomerações do tipo Alto-Alto mais relevantes são aquelas localizadas na RMPA e outra menor na Região Sudoeste, conforme a Figura 7. Na primeira podemos mencionar tais municípios: Porto Alegre, Viamão, Barra do Ribeiro, Imbé, Palmares do Sul, Guaíba, Alvorada, entre outros. Na segunda temos: Rosário do Sul e São Gabriel.

Em 2010 a associação espacial é bastante modificada em relação ao ano anterior. Os clusters do tipo Baixo-Baixo se estendem da Região Noroeste a Centro Oriental em sua maioria. Enquanto que os de tipo Alto-Alto se estendem da RMPA até a Região Nordeste. Sobre o agrupamento de tipo Baixo-Baixo evidenciam-se os seguintes municípios: Três de Maio, São Miguel das Missões, Pontão, Cerro Largo, Dois Irmãos das Missões etc. Já o grupo associativo Alto-Alto é dado por algumas cidades, sendo elas: Caxias do Sul, Canela, Cambará do Sul, Gramado, Igrejinha, Porto Alegre, Gravataí, Novo Hamburgo, Viamão, Alvorada, Canoas, entre outras.

Figura 7 - Clusters para a Taxa de Tráfico de Drogas nos Anos de 2002, 2010 e 2018 2002 2010 2018
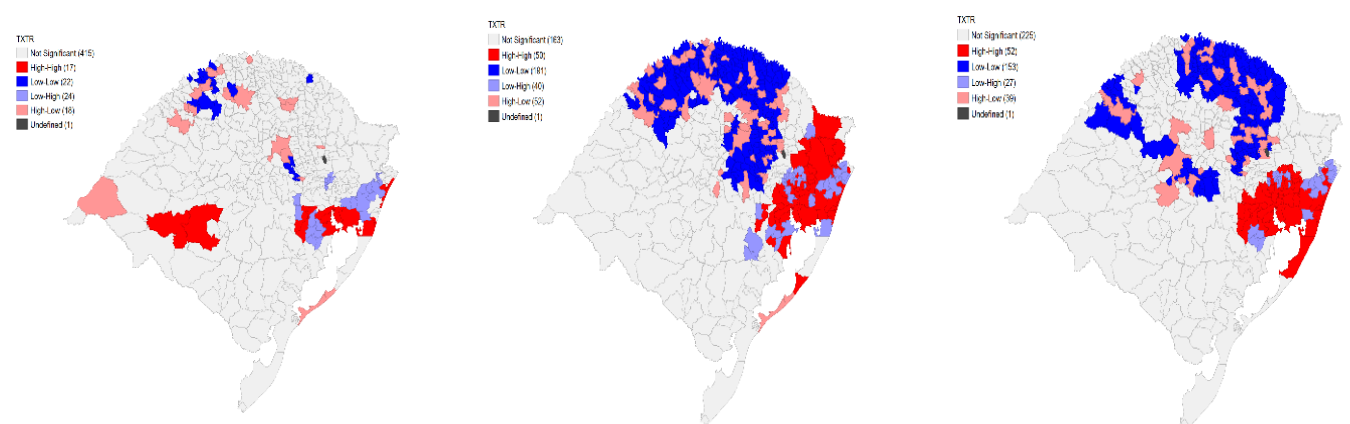

Fonte: Elaboração própria usando o software GeoDa 1.14.

Por fim, em 2018 os clusters do tipo Alto-Alto se localizam principalmente na RMPA e em quase todo o Litoral Gaúcho. Os de tipo Baixo-Baixo em grande parte se localizam nas fronteiras com o estado de Santa Catarina, na Região Noroeste e em parte na Região Central. Daqueles de tipo Alto-Alto podemos mencionar alguns municípios: Gramado, Porto Alegre, Viamão, Alvorada, Canoas, Palmares do Sul, Triunfo, Portão, 
Taquara, Parobé, Igrejinha etc. Aqueles de tipo Baixo-Baixo têm-se: Tupanciretã, Candelária, Nova Palma, São José do Ouro, Viadutos, Nonoai, Palmeira das Missões etc. Ainda destacam as cidades de tipo Baixo-Alto e Alto-Baixo. Do primeiro grupo observase: Cerro Grande do Sul, Feliz, Rolante, Riozinho, Santa Maria do Herval entre outros. Do segundo é possível mencionar os seguintes: Santa Maria, Cruz Alta, São Luiz Gonzaga, Frederico Westphalen, Erechim, Lagoa Vermelha, Arvorezinha, Antônio Prado, entre outros.

Assim, inicialmente não havia muitos aglomerados no estado, porém, com o passar do tempo, com o aumento gradativo das ocorrências, nota-se que a extensão dos clusters do tipo Alto-Alto se expandiu para RMPA e os de tipo Baixo-Baixo se concentram entre as regiões Noroeste, parte do Nordeste e Central. Conforme mencionado anteriormente, centros urbanos e cidades de maior porte facilitam o intercâmbio de informações e a organização da atividade criminosa, além de dificultar a identificação dos traficantes, o que pode contribuir para a concentração desse tipo de crime nas regiões mais populosas. Além disso, assim como o roubo, o tráfico caracteriza-se como um crime de motivação financeira e a RMPA concentra a maior geração de riqueza do estado, atraindo criminosos.

\section{Conclusão}

Esta pesquisa teve por objetivo realizar uma análise espacial da criminalidade para as cidades do Rio Grande do Sul, averiguando a formação de clusters espaciais nos anos de 2002, 2010 e 2018. Os resultados indicaram a existência de dependência espacial nos crimes de roubos e tráfico de entorpecentes, embora nem todos os municípios do Estado apresentaram significância.

A composição de clusters com correlação do tipo Alto-Alto é majoritariamente concentrada na Região Metropolitana de Porto Alegre (RMPA) para a taxa de homicídios, roubos e tráfico de entorpecentes, evidenciando, assim, a problemática da violência em um dos principais centros urbanos do país ao longo dos anos observados. Esse resultado corrobora com a hipótese que a RMPA é capaz de desenvolver uma rede de incentivos que favoreçam a atividade criminosa se comparada a outras regiões do estado gaúcho, por exemplo, o anonimato, a redução da assimetria de informações, o custo de oportunidade, o custo de planejamento, entre outros. Já a formação dos agrupamentos espaciais do tipo Baixo-Baixo se deu, em sua maioria, nas regiões Noroeste e Nordeste do Rio Grande do Sul, onde muitos são municípios de fronteira com Santa Catarina.

Em todos os crimes obtive-se coeficientes I de Moran positivos, ou seja, cidades com elevada taxa de crimes estão associadas espacialmente por outras cidades com alta taxa de crimes. O mesmo raciocínio se aplica a situação inversa. A taxa de homicídios foi 
o crime que apresentou o menor grau de correlação se comparada à taxa de roubos e tráfico de entorpecentes.

Sendo assim, evidencia-se que ainda existe um vasto campo a ser explorado no tocante a criminalidade regional dada sua complexidade, tanto no que diz respeito à agregação de novos aspectos espaciais quanto às outras abordagens que são discutidas na literatura econômica. O amadurecimento dessa área temática é fundamental para que sejam desenvolvidas políticas públicas de médio e longo prazo a fim de prevenir e combater a criminalidade de maneira coordenada e racional. O presente estudo se limitou a analisar a correlação espacial do crime, sem analisar os determinantes deste, de modo a orientar as políticas públicas de forma mais específica. Nesse sentido, uma sugestão para estudos futuros seria a estimação de um modelo do crime com dados em painel espacial dos municípios, analisando as variáveis que podem ser determinantes das taxas de crime no Estado. Contudo, para isso, ainda se faz necessário que o poder público amplie a disponibilidade de informações socioeconômicas e de criminalidade dos municípios, para que os estudos futuros possam ser cada vez mais robustos.

\section{Referências Bibliográficas}

ALMEIDA, E. Econometria Espacial Aplicada. Campinas: Editora Alínea, v. 1, 2012. ISBN 978-85-7516-601-7.

ATLAS DA VIOLÊNCIA. Atlas da Violência, 2019. Disponivel em: <http://www.ipea.gov.br/atlasviolencia/>. Acesso em: 24 Outubro 2019.

BECKER, G. S. Crime and Punishment: An Economic Approach. Journal of Political Economy, v. 76, p. 169-217, 1968.

DOI: https://doi.org/10.1086/259394

BECKER, K. L.; KASSOUF, A. L. Uma análise do efeito dos gastos públicos em educação sobre a criminalidade no Brasil. Economia e Sociedade, Campinas, v. 59, n. 1, p. 215-242, Abril 2017.

DOI: http://dx.doi.org/10.1590/1982-3533.2017v26n1art8

BRASIL. Os Custos Econômicos da Criminalidade no Brasil. Secretaria Geral da Presidência. Brasília, p. 1-76. 2018.

BRONFENBRENNER, U. A. Ecologia do Desenvolvimento Humano: experimentos naturais planejados. Porto Alegre: Artes Médicas, 1996. (Originalmente publicado em 1979). 
BRUNET, J. F. G. et al. Fatores preditivos da violência na Região Metropolitana de Porto Alegre. Revista Brasileira de Segurança Pública, v. 2, n. 1, p. 70-90, Jul/Ago 2008. ISSN ISSN 1981-1659.

CARRETS, F. D.; OLIVEIRA, J. D.; MENEZES, G. R. A Criminalidade no Rio Grande do Sul: uma análise espacial para anos de 2005, 2010 e 2015. Perspectiva Econômica, v. 14, n. 1, p. 33-46, Jan-Jun 2018.

DOI: https://doi.org/10.4013/pe.2018.141.03

CLEMENTE, A.; WELTERS, A. Reflexões sobre o modelo original da Economia do Crime. Revista de Economia, v. 33, p. 139-157, jul/dez 2017.

COSTA, F.; ADORNO, L. Mapa das Facções no Brasil: PCC e Comando Vermelho disputam hegemonia do crime em 9 estados, 22 Agosto 2018. Disponivel em:

<https://noticias.uol.com.br/cotidiano/ultimas-noticias/2018/08/22/mapa-das-faccoes-nobrasil-pcc-e-comando-vermelho-disputam-hegemonia-do-crime-em-9-estados.htm>. Acesso em: 17 Outubro 2019.

DEPEN. Departamento Penitenciário Nacional, 2017. Disponivel em:

<http://depen.gov.br/DEPEN/depen/sisdepen/infopen/relatorios-analiticos/RS/rs>. Acesso em: 24 Outubro 2019.

EHRLICH, I. Participation in Illegitimate Activities: A Theoretical and Empirical Investigation. Journal of Political Economy, v. 81, n. 3, p. 521-565, 1973.

DOI: https://doi.org/10.1086/260058

FEE. Fundação de Economia e Estatística, 14 Dezembro 2017. Disponivel em: <https://www.fee.rs.gov.br/indicadores/pib-rs/municipal/destaques/>. Acesso em: 17 Outubro 2019.

FRANCO, C. Revisão de Literatura e Evidencias Empíricas Sobre Economia do Crime. Revista UNEMAT de Contabilidade, v. 5, n. 9, p. 154-175, Jan./Jul. 2016. ISSN 23168072. DOI: https://doi.org/10.30681/ruc.v5i9.813

HARTUNG, G.; PESSOA, S. Fatores demográficos como determinantes da criminalidade. XXXV Encontro Nacional de Economia ANPEC, Recife, 23 Julho 2007. 1-19.

MENDONÇA, M. J. C. D. Criminalidade e Violência no Brasil: Uma Abordagem Teórica. Revista Brasileira de Economia de Empresas, v. 2, n. 1, p. 34-49, Jan/Mai 2002.

OLIVEIRA, C. A. D. Criminalidade e o Tamanho das Cidades Brasileiras: Um Enfoque da Economia do Crime. XXXIII Encontro Nacional de Economia ANPEC, Natal, n. 152, Dezembro 2005. 1-23. 
OLIVEIRA, C. A. D. Análise espacial da criminalidade no Rio Grande do Sul. Revista de Economia, v. 34, n. 3, p. 35-60, Dezembro 2008.

OLIVEIRA, J. D.; CARRETS, F. D.; FREITAS, T. A. D. Estimação de um Índice de Criminalidade dos muncípios do Rio Grande do Sul nos anos de 2005-2015, IGCrime RS. XX Encontro de Economia da Região Sul, Porto Alegre, 2017.

PINTO, N. G. M.; CORONEL, D. A.; FILHO, R. B. A criminalidade no Rio Grande do Sul: Um estudo sobre os tipos de crime e aspectos do desenvolvimento regional no período de 2007 a 2010. Economia e Gestão, Belo Horizonte, v. 16, n. 45, p. 58-77, Dezembro 2016. ISSN 1984-6606.

DOI: https://doi.org/10.5752/P.1984-6606.2016v16n45p58

SANTOS, M. J. D.; KASSOUF, A. L. Uma Investigação Econômica da Influência do Mercado de Drogas Ilícitas Sobre a Criminalidade Brasileira. Revista EconomiA, Brasília, v. 8, n. 2, p. 187-210, Mai./Ago. 2007.

SANTOS, M. J. D.; SANTOS, J. I. D. Convergência das Taxas de Crimes no Território Brasileiro. Revista EconomiA, Brasília, v. 12, n. 1, p. 131-147, Jan-Abr 2011.

SANTOS, M. J.; KASSOUF, A. L. Menos desemprego, maior eficiência da polícia e redução da criminalidade em São Paulo. $3^{\circ}$ Encontro Nacional de Economia ANPEC, Foz do Iguaçu, 21 Julho 2011.

SCHAEFER, G. J.; SHIKID, P. F. A. Economia do crime: elementos teóricos e evidencias empíricas. Análise Econômica, Porto Alegre, 19, n. 36, Março 2001. 1-25. DOI: https://doi.org/10.22456/2176-5456.10682

WILSON, J. Q.; HERRNSTEIN, R. Crime and Human Nature: The Definitive Study of the Causes of Crime. 1. ed. [S.1.]: Simon \& Schuster, 1985. ISBN 0671628100.

ZALUAR, A. A abordagem ecológica e os paradoxos da cidade. Revista de Antropologia. Antropologia, São Paulo, v. 53, n. 2, p. 611-644, 2010.

DOI: https://doi.org/10.11606/2179-0892.ra.2010.37712 


\section{Apêndice A - Diagrama de Dispersão de Moran (Homicídios)}

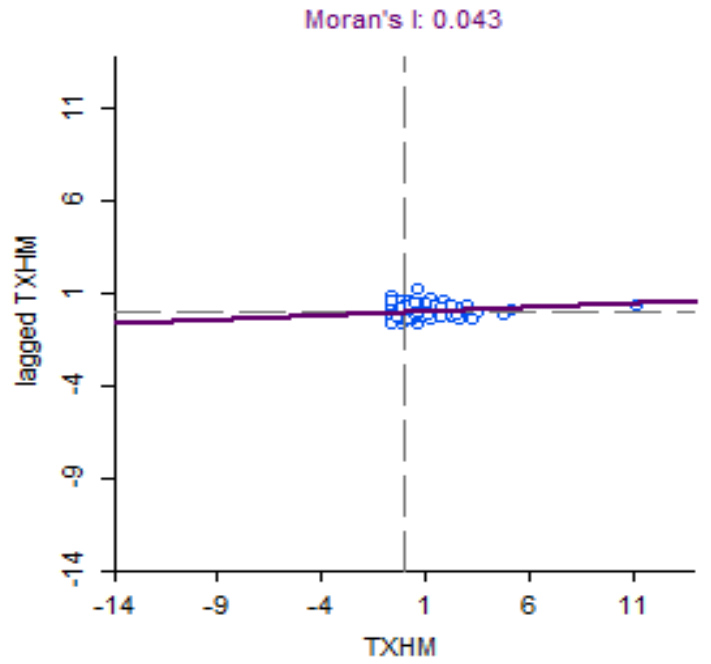



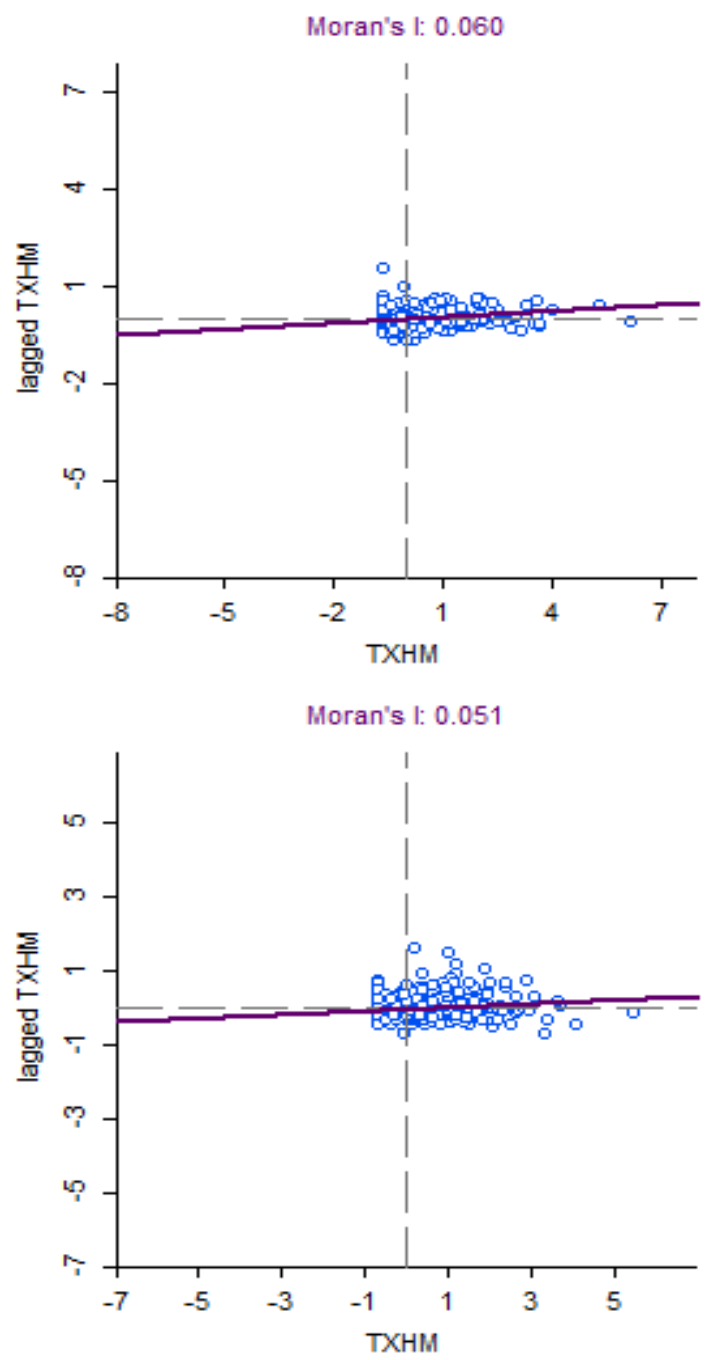


\section{Apêndice B - Diagrama de Dispersão de Moran (Roubos)}
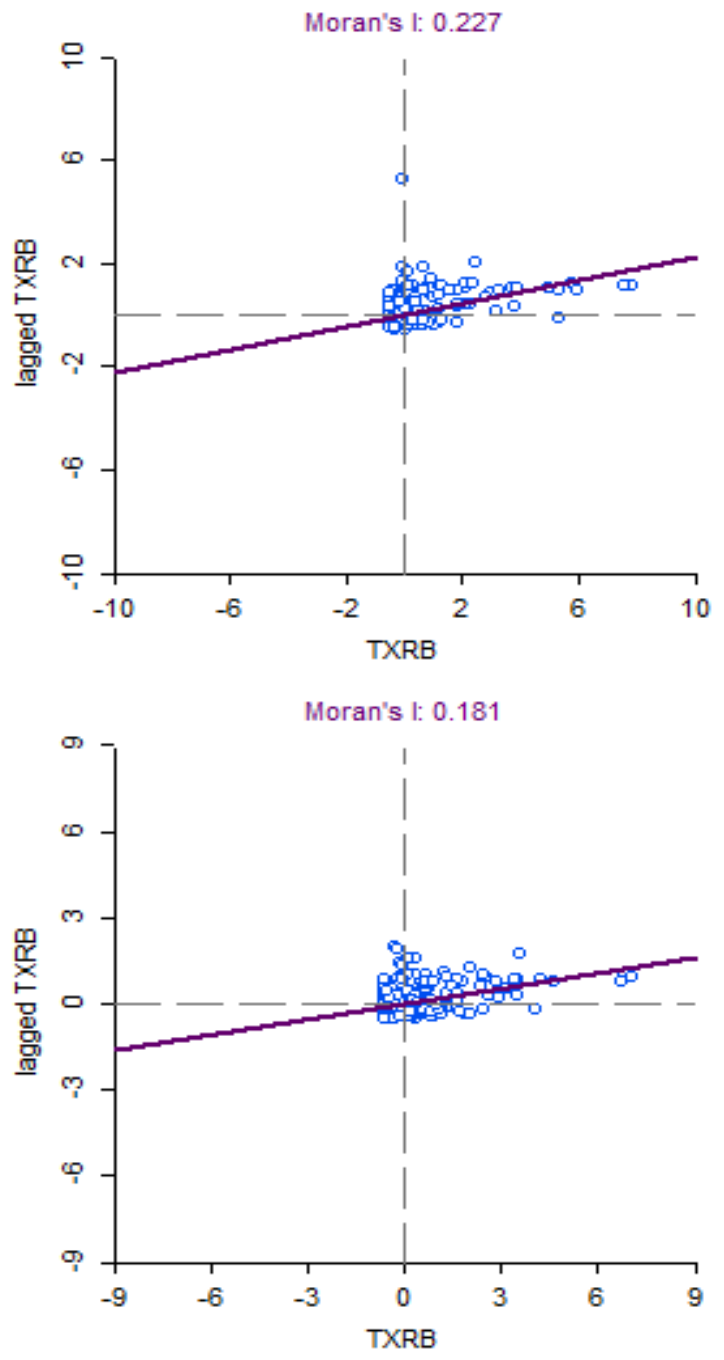


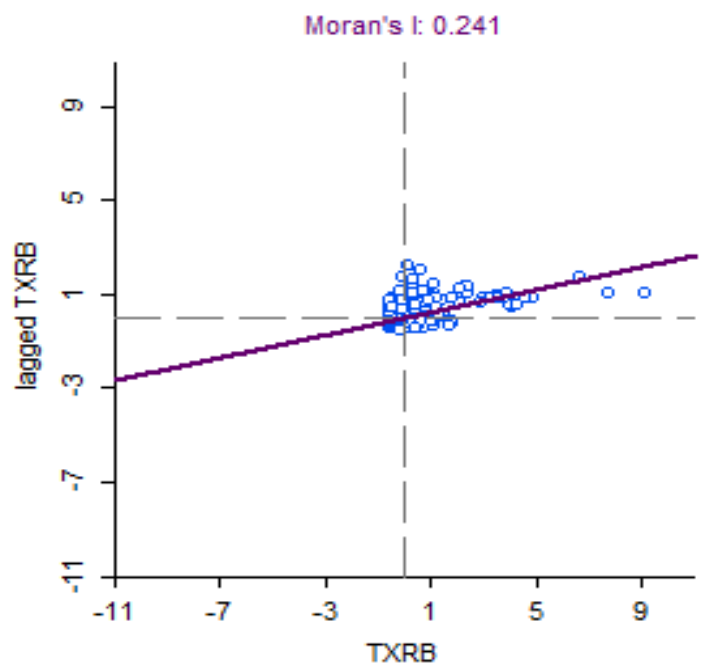

\section{Apêndice C - Diagrama de Dispersão de Moran (Tráfico)}

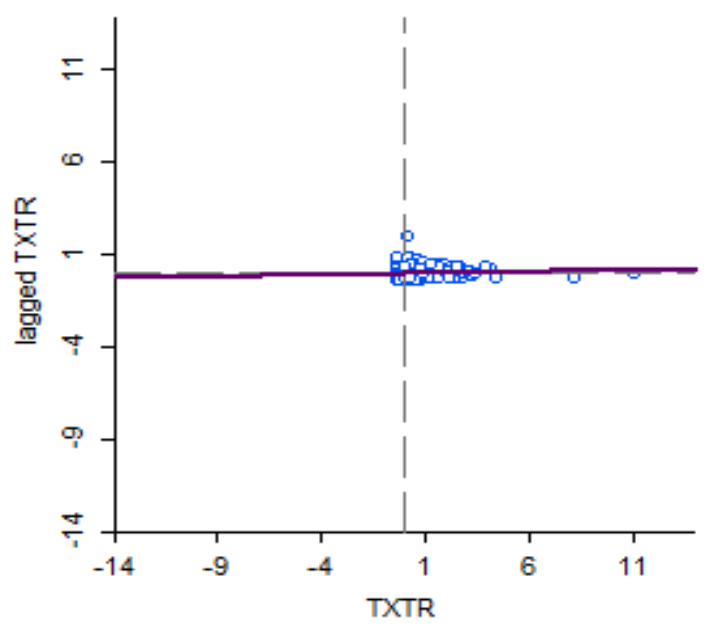



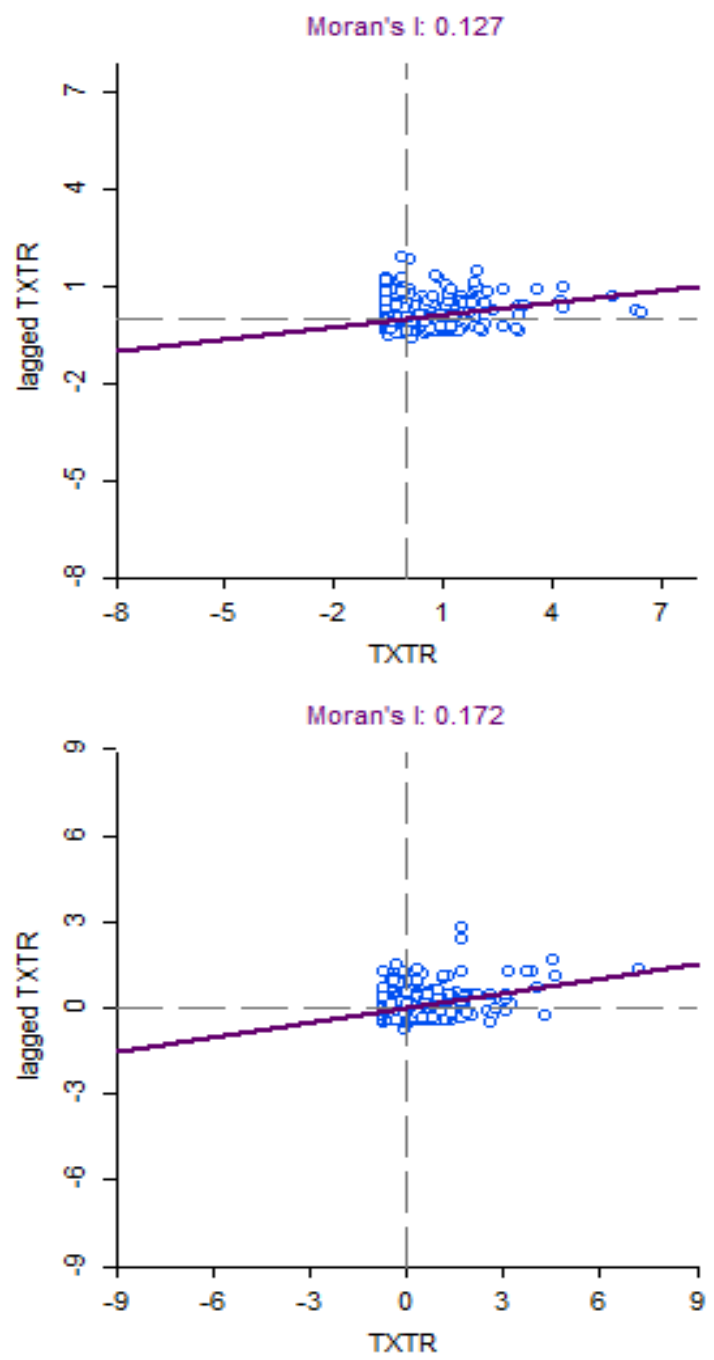